\title{
Glass Half Full
}

lons

this issue, O'Connor and colleagues ${ }^{1}$ report a study on the

efficacy of double-blind peer review in the American Journal of Neuroradiology (AJNR). They found that $12.7 \%$ of reviewers thought or suspected that they knew the authors' identities. Most of the time when the reviewers thought they knew, they didsome $90 \%$ chose correctly. Several questions and interesting points are raised by this article:

1) Does this mean peer review doesn't work and that doubleblind peer review is going away in AJNR? No.

Keep in mind that approximately $87 \%$ of the time, the blind held. Being a glass-half-full person, and knowing firsthand the incredible variety of manuscripts and writing styles that we encounter, that number seems a remarkably good data point. The literature attests to the overall high quality of the blinding process as it is applied in the $A J N R$, with previous publications reporting the blind can be broken $25 \%-46 \%$ of the time. ${ }^{2,3}$ The AJNR currently has the lowest rate of unblinding in the literature.

2) When the blind is broken, does it harm the author's chance of having the manuscript accepted? Interestingly, this would seem to increase the chance of publication. There may be bias involved, but the bias helps the author. This effect has also been previously reported in that proportionally fewer manuscripts are published when there is no idea of the author's identity versus knowing the identity. ${ }^{3,4}$ Perhaps the confounding aspect of the unblinding is that the well-known authors are well known for a very good reason, such as consistently producing good science.

3) As pointed out in the article, some of the onus is on us as the editors and staff to correctly modify the incoming articles to make them more neutral, where possible. Some of the onus, however, is on the author to write in a neutral style that does not include obvious self-citation or specific identifying information. You are proud of your previous work, and that work may have formed the basis for your current research, but keep the concept of doubleblind review in your mind as the manuscript is written.

Sometimes, it is not possible to adequately blind the manuscript without gutting the manuscript of the necessary background information the reviewer will need to make an informed decision. The following are a few examples we have encountered in the past few months (scrubbed and sanitized to protect the innocent). How would you deal with these cases?

- Referencing a previously published patient cohort to either report a subset analysis or to reference the cohort demographics, inclusion criteria, outcome measures, etc.

- Use of prior publication conclusions to justify the current manuscript (eg, a recent study of X showed differences in $\mathrm{Y}$, which we evaluated in this study of $Z$ ).

- Data from the previous intervention $X$ have been reported.

- This study is part of the XYZ Foundation study into imaging of Q.

- Intervention $\mathrm{X}$ is the standard management of $\mathrm{Q}$ at our institution.

- We have used the XYZ sequence as previously performed by Q.

- A population-based study of XYZ imaging located in the Kingdom of Latveria. (Gold star if you recognize this location without a search engine.)

As $\mathrm{O}^{\prime}$ Connor et $\mathrm{al}^{1}$ concluded, "the double-blind peer review process used at AJNR effectively maintains double anonymity in most instances." We will continue to strive for better blinding on the editorial side, and with you on the author side, that is a realistic goal. To paraphrase Winston Churchill's democracy quote: Double-blind peer review is the worst form of review, except all the others that have been tried.

\section{REFERENCES}

1. O'Connor EE, Cousar M, Lentini JA, et al. Efficacy of double-blind peer review in an imaging subspecialty journal. AJNR Am J Neuroradiol 2016 Nov 17. [Epub ahead of print] CrossRef

2. Fisher M, Friedman SB, Strauss B. The effects of blinding on acceptance of research papers by peer review. JAMA 1994;272:143-46 CrossRef Medline

3. Isenberg SJ, Sanchez E, Zafran KC. The effect of masking manuscripts for the peer-review process of an ophthalmic journal. Br J Ophthalmol 2009;93:881-84 CrossRef Medline

4. Okike K, Hug KT, Kocher MS, et al. Single-blind vs double-blind peer review in the setting of author prestige. JAMA 2016;316:1315-16 CrossRef Medline

(1)J.S. Ross

Editor-in-Chief

http://dx.doi.org/10.3174/ajnr.A5047 